\title{
A testing approach based on tiny doses still awaits big results
}

For a drug to work, the body must first absorb it. But pharmaceutical companies still spend millions of dollars a year developing drug candidates that fail to pass this simple step. With this in mind, the bioscience company Xceleron recently conducted one of the first comparative human 'microdose' studies. The company presented its results at a conference held by the European Federation for Pharmaceutical Sciences this past June in Bad Homburg, Germany.

According to the controversial new method known as microdosing, microgram-sized quantities of a drug are delivered to human subjects long before safety and efficacy trials have begun. This is possible because in the US, for example, Food and Drug Administration (FDA) regulations typically allow drug quantities of less than 100 micrograms to be tested in humans, so long as a standard Investigational Drug Application has been filed. Depending on the drug sponsor's clinical goals, varying degrees of toxicology research must also be conducted. "Yet because the risk from a microdose study is small compared to a traditional phase 1 study, much less preclinical data is required," says David Jacobson-Kram, director of toxicology at the FDA's Office of New Drugs.

To test such low concentrations of the drug, samples are usually labeled with a radioactive tag and then traced through the urine and blood by a technique called accelerator mass spectrometry. "This helps pharmaceutical companies predict whether the final drug product will be absorbed," says Colin Garner, the chief executive officer of the Germantown, Maryland-based Xceleron. "Expensive animal studies can be avoided if the drug proves unsuccessful early on," he adds.

Yet proponents and critics alike say that microdosing methods must be further validated. One central question is whether the body metabolizes small doses differently. "It's amazing technology," says Jacobson-Kram, "but it's too early to tell whether microdosing will predict what happens when you give a pharmaceutical dose, which is orders of magnitude larger."

In 2005, in response to this same question, the European Union commissioned a study that compared the micro- and pharmaceutical doses. Xceleron spearheaded the $€ 2$ million (\$3 million) effort and selected seven wellknown drug compounds for analysis, such as the antihistamine fexofenadine, sold as Allegra. Each drug was tested in six different subjects who received an intravenous microdose of radiolabeled drug alongside a traditional, oral pill.

Garner told Nature Medicine that the microdose data predicted the degree of the body's absorption for five of the seven tested compounds. "While the findings are preliminary, the data is consistent with what we have seen in the past," says Garner. Previously, the company found that microdosing predicted drug absorption for four out of five other compounds (Clin. Pharmacol. Ther. 80, 203-215; 2006).

"Traditional animal models are only 50\% effective at predicting whether a drug will be bioavailable in human systems," Garner adds.

Yet Steven Tannenbaum, a chemist at the Massachusetts Institute of Technology in Cambridge, Massachusetts, points out that the company has not yet released the specific criteria used for defining similarity between the most recent seven micro- and pharmaceutical doses.

Moreover, even if a drug is bioavailable, it can still be toxic or ineffective, says Tannenbaum. And bioavailability is not a sure predictor of success, as some drugs with low bioavailability prove effective. "According to their success rates, there is a $20 \%$ chance Xceleron's bioavailability data is wrong anyway," points out Tannenbaum. "While better methods are being developed, microdose studies are still very limited," he says, though he adds that accelerator mass spectrometry technology might help researchers monitor the byproducts of a drug (Anal. Chem. 80, 5079-5085; 2008).

Amy Coombs, San Francisco

\section{Massachusetts pours money into local life sciences research}

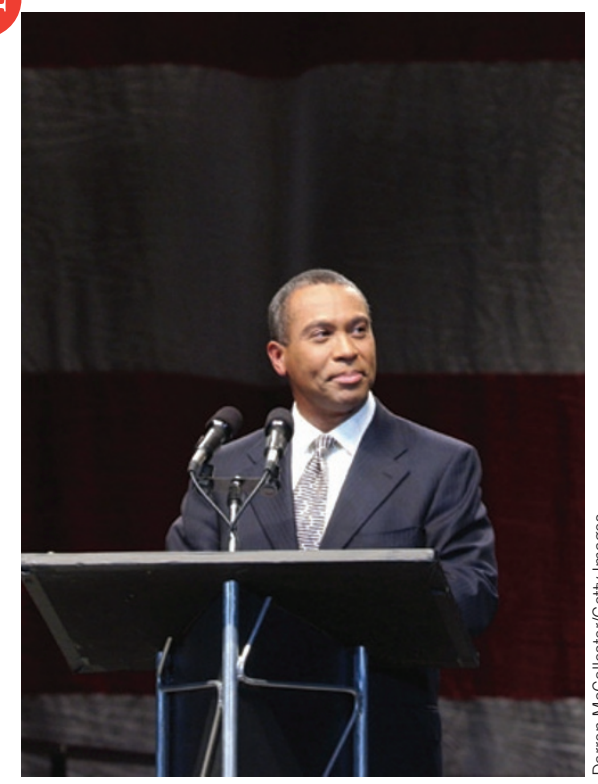

Standing for science: Governor Deval Patrick
All eyes are on an experiment aimed at boosting local biomedical research in Massachusetts. In June, the state's governor, Deval Patrick, signed the $\$ 1$ billion Massachusetts Life Sciences Law, which consists of $\$ 250$ million in tax incentives for life science companies, $\$ 250$ million in grants and $\$ 500$ million toward related infrastructure. Patrick says the law will fund research ventures needing a boost at a crucial phase-the transition from the proof of a concept to its commercialization. "A lot of good ideas die there, and the bill tries to plug those funding gaps," Patrick told Nature Medicine.

"Our community of biomedical investigators is energized by this infusion of state funding and [is] committed to translating fundamental scientific discoveries made at the bench into life-changing therapeutics at the bedside," says Craig Mello of the University of Massachusetts Medical School at Worcester and winner of the 2006 Nobel Prize in medicine.

The new law will benefit a wide swath of the biotech sector in that state, including research institutions, teaching hospitals and pharmaceutical companies, according to Daniel O'Connell, the state's secretary of housing and economic development. "We believe we are currently the worldwide 'supercluster' in the industry, but other states and countries are trying to attract our talent and businesses," O'Connell says. "The goal of the law is to ensure that we don't lose our position of preeminence."

O'Connell notes that distributing the grants on merit will be a challenge. A scientific advisory committee headed by Harvey Lodish of the Massachusetts Institute of Technology will review grant applications by peer review and make recommendations to a board that O'Connell currently chairs. The grants- to be distributed over ten years-will, for example, help create a stem cell bank and facilities for gene therapy and RNA interference research at the University of Massachusetts Medical School.

Prashant Nair, Boston 